\title{
The Negative Effect of Mean Perfusion Pressure on the Development of Acute Kidney Injury after Transcatheter Aortic Valve Implantation
}

Ilker Gül' , MD; Levent Cerit ${ }^{1}$, MD; Bihter Senturk², MD; Mustafa Zungur ${ }^{3}$, MD; Mustafa Beyazıt Alkan ${ }^{4}$, MD; Hatice

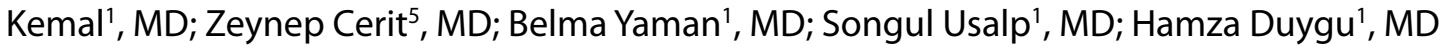

\begin{abstract}
Objective: To evaluate the predictive value of mean perfusion pressure (mPP) in the development of acute kidney injury (AKIN) after transcatheter aortic valve implantation (TAVI).

Methods: One hundred and forty seven consecutive patients with aortic stenosis (AS) were evaluated for this study and 133 of them were included. Mean arterial pressure (mAP) and central venous pressure (CVP) were used to calculate mPP before TAVI procedure $(\mathrm{mPP}=\mathrm{mAP}-\mathrm{CVP})$. The occurrence of AKIN was evaluated with AKIN classification according to the Valve Academic Research Consortium-2 recommendations. The patients were divided into two groups according to the receiver operating characteristic (ROC)
\end{abstract}

analysis of their mPP levels (high-risk group and low-risk group). Results: The AKIN prevalence was $22.6 \%$ in this study population. Baseline serum creatinine level, glomerular filtration rate, amount of contrast medium, and the level of mPP were determined as predictive factors for the development of AKIN.

Conclusion: The occurrence of AKIN is associated with increased morbidity and mortality rates in patients with TAVI. In addition to the amount of contrast medium and basal kidney functions, our study showed that lower mPP was strongly associated with development of AKIN after TAVI.

Keywords: Transcatheter Aortic Valve Replacement. Kidney. Acute Kidney Injury. Perfusion.

\begin{tabular}{llll}
\hline \multicolumn{2}{l}{ Abbreviations, acronyms \& symbols } & & \\
\hline AKIN & $=$ Acute kidney injury & GFR & $=$ Glomerular filtration rate \\
AR & $=$ Aortic regurgitation & HR-G & $=$ High-risk group \\
AS & $=$ Aortic stenosis & LR-G & $=$ Low-risk group \\
AUC & $=$ Area under the curve & mAP & $=$ Mean arterial pressure \\
AVA & $=$ Aortic valve area & mPP & $=$ Mean perfusion pressure \\
CAD & $=$ Coronary artery disease & NRF & $=$ Normal renal functions \\
CHF & $=$ Congestive heart failure & PCI & $=$ Percutaneous coronary intervention \\
CI & $=$ Confidence interval & RBC & $=$ Red blood cell \\
CM & $=$ Contrast mediums & ROC & $=$ Receiver operating characteristic \\
COPD & $=$ Chronic obstructive pulmonary disease & SAVR & $=$ Surgical aortic valve replacement \\
CrCI & $=$ Creatinine clearance & SBP & $=$ Systolic blood pressure \\
CVP & $=$ Central venous pressure & STS & $=$ Society of Thoracic Surgeons \\
CT & $=$ Computed tomography & TAVI & $=$ Transcatheter aortic valve implantation \\
DBP & $=$ Diastolic blood pressure & VARC-2 & $=$ Valve Academic Research Consortium-2 \\
DM & $=$ Diabetes mellitus & & \\
\hline
\end{tabular}

'Near East University, Faculty of Medicine, Department of Cardiology, Nicosia, Cyprus. 2Dokuz Eylül University, Faculty of Medicine, Department of Cardiology, Izmir, Turkey.

${ }^{3}$ Kent Hospital, Cardiology Clinic, Izmir, Turkey.

${ }^{4}$ Kas State Hospital, Antalya, Turkey.

${ }^{5}$ Near East University, Faculty of Medicine, Department of Pediatric Cardiology, Nicosia, Cyprus.

This study was carried out at Near East University Hospital, Near East Boulevard, Nicosia, Cyprus.
No financial support

No conflict of interest.

Correspondence Address:

Levent Cerit

Near East University Hospital

Near East Boulevard, Nicosia, Cyprus - Zip Code: 99138

E-mail: drcerit@hotmail.com

Article received on April 2nd, 2018 Article accepted on May 29th 2018. 


\section{INTRODUCTION}

Aortic stenosis (AS) is one of the most common cardiac degenerative valvular diseases, with a prevalence of 3-5\% in patients above 75 years of age ${ }^{[1]}$. Surgical aortic valve replacement (SAVR) is currently considered the gold standard treatment for severe symptomatic $\mathrm{AS}^{[2]}$. Transcatheter aortic valve implantation (TAVI) has emerged as an alternative to surgery for patients with severe symptomatic AS, particularly for those who were considered at intermediate to high risk for surgery ${ }^{[3,4]}$. Since its introduction in 2002, more than 200,000 patients have undergone TAVI globally.

Ageing, preexisting impaired kidney function, hemodynamic instability, congestive heart failure (CHF), diabetes mellitus (DM), anaemia, and the usage of great amount of contrast mediums (CM) are well-known risk factors for the development of acute kidney injury (AKIN) after TAVI[5,6].

Although these risk factors have been well known, the predictive value of mean perfusion pressure (mPP) in the development of AKIN has not been investigated yet. Therefore, in this study, we aimed to evaluate the predictive value of mPP in the development of AKIN after TAVI.

\section{METHODS}

In this study, 147 consecutive patients who had undergone TAVI procedure in our clinic between June 2013 and December 2015 were evaluated. One hundred and thirty three of them met the inclusion criteria and were included in this study. Patients who had invasive blood pressure monitorization, jugular venous catheter, and were hemodynamically stable were included in our study. Patients who had undergone renal replacement therapy, presented glomerular filtration rate (GFR) $<30 \mathrm{ml} / \mathrm{min} / 1.73 \mathrm{~m}^{2}$, had decompensated heart failure, received inotropic agents, had intra-aortic balloon pump, and received CM within the last 48 hours were excluded. Patients who had undergone additional procedures or received additional CM due to vascular complications, and had chronic pulmonary diseases or chronic liver diseases were also excluded from the study. Intravenous hydration therapy was started in patients with GFR $<50 \mathrm{ml}$ $\mathrm{min} / 1.73 \mathrm{~m}^{2}$ for 12 hours before the procedure and continued for 24-48 hours after TAVI. Patients' daily blood tests including creatinine were checked for three days before and three days after TAVI.

\section{Mean Perfusion Pressure}

Blood pressure of every patient was monitored using invasive monitorization during the 12 hours before TAVI procedure. Also during this period, mean arterial pressure (mAP) calculated by monitors was entered in patient files. Central venous pressure (CVP) was monitored with catheters implanted by anesthesiologists in all patients before valve implantation. The $\mathrm{mPP}$ was calculated using the formula MPP $=$ mAP-CVP.

\section{Acute Kidney Injury}

The Valve Academic Research Consortium-2 (VARC-2) criteria were used to evaluate any complication occuring in TAVI patients ${ }^{[7]}$. VARC-2 recommends that the AKIN system should be used to diagnose AKIN. According to the AKIN system:

- AKIN Stage 1: Increase in serum creatinine of 150-199\% (1.5$1.99 \times$ increase compared with baseline) or increase of $\geq 0.3$ $\mathrm{mg} / \mathrm{dL}$ ( $\geq 26.4 \mathrm{mmol} / \mathrm{L}$ ) or urine output $<0.5 \mathrm{~mL} / \mathrm{kg} / \mathrm{h}$ for $>6 \mathrm{~h}$ but $<12 \mathrm{~h}$;

- AKIN Stage 2: Increase in serum creatinine of 200-299\% (2.0$2.99 \times$ increase compared with baseline) or urine output $<0.5$ $\mathrm{mL} / \mathrm{kg} / \mathrm{h}$ for $>12 \mathrm{~h}$ but $<24 \mathrm{~h}$;

- AKIN Stage 3: Increase in serum creatinine of $\geq 300 \%$ (>3 $\times$ increase compared with baseline) or serum creatinine of $\geq 4.0$ $\mathrm{mg} / \mathrm{dL}(\geq 354 \mathrm{mmol} / \mathrm{L})$ with an acute increase of at least 0.5 $\mathrm{mg} / \mathrm{dL}$ (44 mmol/L) or urine output $<0.3 \mathrm{ml} / \mathrm{kg} / \mathrm{h}$ for $>24 \mathrm{~h}$ or anuria for $>12 \mathrm{~h}$.

\section{TAVI Procedure}

Severe AS was diagnosed with echocardiographic methods. The situations of average aortic gradient $>40 \mathrm{mmHg}$, aortic valve area (AVA) $<1 \mathrm{~cm}^{2}$, and valve area index (valve area/body surface area) $<0.6 \mathrm{~cm}^{2}$ were considered to be severe $A S^{[8]}$. The balloonexpandable Edwards Sapien XT valve (Edwards Lifesciences, Irvine, California, USA) was used for TAVI process. Vascular occlusion device (ProStar XL, Abbott Laboratories, North Chicago, Illinois, USA) was used in eligible patients in terms of femoral artery diameter and anatomy. The surgical cut-down method was applied in patients who were unsuitable for using iliac and femoral artery anatomy vascular closure device. Transoesophageal echocardiography and multislice computed tomography (CT) tests were done to determine the diameter of the aortic bioprosthesis implanted. In all patients, clopidogrel $75 \mathrm{mg}$ and acetylsalicylic acid $100 \mathrm{mg}$ were started before TAVI procedure. İohexol (Omnipaque, GE Healthcare), a nonionic low-osmolar monomeric CM, was used as the opaque material. The amount of CM was recorded during all TAVI procedure. Examinations such as $C T$ and coronary angiography that required administration of $C M$, except TAVI procedures, were performed at least 72 hours before. Daily kidney function tests of all patients were monitored in our centre from admission to discharge. Creatinine levels were checked in the second week, and the first, third, sixth and twelfth month after TAVI procedure (COBAS Integra 400 plus, Roche Diagnostics).

The patients were prospectively followed during one year after TAVI. The informed consent form was obtained from each subject, and the study was conducted in accordance with the Helsinki Declaration. The study protocol was approved by the local ethics committee.

\section{Study Groups}

Based on the receiver operating characteristic ( $\mathrm{ROC})$ analysis, patients who had lower mPP values ( $<72 \mathrm{mmHg}$ ), which was determined as the threshold value for AKIN development, were included in the high-risk group ( $\mathrm{HR}-\mathrm{G}$ ), and those who had higher $\mathrm{mPP}$ values ( $\geq 72 \mathrm{mmHg}$ ) were included in the low-risk group (LR-G). Additionally, characteristics of patients with normal renal functions (NRF) and those who developed AKIN were evaluated. 


\section{Statistical Analysis}

Statistical analysis was performed using SPSS 17.0 software (SPSS, Chicago, Illinois, USA). The Kolmogorov-Smirnov test was used to assess the normality of distributions. Variables not normally distributed were expressed as medians (interquartile ranges). Normally distributed continuous variables were expressed as a mean \pm standard deviation. The means for normally distributed continuous variables were compared by independent-samples t-tests. Skew-distributed continuous variables were compared using a Mann-Whitney $U$ test. Pearsons $x^{2}$ test and Fisher exact test were used to compare categorical variables. Univariate analyses were performed with the variables, such as age (years), left ventricular ejection fraction (\%), mean aortic gradient $(\mathrm{mmHg})$, Society of Thoracic Surgeons (STS) score (\%), logistic EuroSCORE (\%), mPP (mmHg), systolic blood pressure (SBP, $\mathrm{mmHg}$ ), diastolic blood pressure (DBP, $\mathrm{mmHg}$ ), DM (\%), hypertension (\%), coronary artery disease (CAD, \%), creatinine $(\mathrm{mg} / \mathrm{dl})$, GFR $\left(\mathrm{ml} / \mathrm{dk} / 1.73 \mathrm{~m}^{2}\right)$, amount of CM $(\mathrm{ml})$, preTAVI haemoglobin levels $(\mathrm{g} / \mathrm{dl})$, and red blood cell transfusion after TAVI (\%). The backward stepwise multivariate regression analysis was performed with the variables of mPP, left ventricular ejection fraction, baseline creatinine, GFR, red blood cell (RBC) transfusion, amount of CM, SBP, and DBP; the $P$ values of those was found to be $P<0.10$, by univariate analyses. A ROC curve analysis was performed to identify the optimal cut-off point of mPP to predict AKIN in patients with severe AS. The area under the curve (AUC) values were calculated as a measure of test accuracy. A two-sided $P<0.05$ was considered significant within a 95\% confidence interval (CI). Kaplan-Meier survival plots were constructed from the index procedure and up to one year after that and compared using the log-rank test. $P$ values $<0.05$ were accepted as statistically significant.

\section{RESULTS}

\section{Patients' General Characteristics}

One hundred and thirty three patients (54.1\% females; mean age of $78.1 \pm 7.5$ years) were enrolled in this study. AKIN was recorded in 30 patients after TAVI (22.6\%). Mean values of SBP, DBP, mAP, and mPP were lower in HR-G and AKIN groups. The mean value of CVP was higher in HR-G and AKIN groups. The average mean gradient of the aortic valve was $49.7 \pm 11.7 \mathrm{mmHg}$, the mean AVA was $0.65 \pm 0.11 \mathrm{~cm}^{2}$, and the mean value of left ventricular ejection fraction was $42 \pm 14.7 \%$.

\section{Procedural Data}

A balloon-expandable Edwards SAPIEN XT valve was implanted via transfemoral access in all patients. The mean radiation time was $7.6 \pm 3.1 \mathrm{~min}$. Mean CM and duration of procedure were $143.4 \pm 22.7$ $\mathrm{ml}$ and $69.2 \pm 28.1 \mathrm{~min}$, respectively. There weren't any significant difference between the two groups according to the numbers and durations of the rapid ventricular pacing.

\section{Mean Perfusion Pressure and Acute Kidney İnjury}

The values of mPP were significantly lower in AKIN patients (65.9 \pm 9.5 vs. $76.3 \pm 7.4 P<0.001)$. Age, gender, DM, hypertension, chronic obstructive pulmonary disease (COPD), CAD, moderate to high grade aortic regurgitation (AR) after $\mathrm{TAVI}$, risk scores for TAVI, haemoglobin, cardiac systolic functions, mean aortic gradient, kidney function tests, amount of CM, previous coronary bypass surgery, and percutaneous coronary intervention (PCl) rates were similar between the two groups. SBP, DBP, mAP, and mPP levels were significantly lower in HR-G group, but CVP level was higher in HR-G group (Table 1).

\section{AKI and Risk Factors}

There was no significant difference between AKIN and NRF groups in terms of CAD, DM, hypertension, and COPD. The AKIN group had longer hospitalisation duration (5.5 vs. 4 days, $P=0.014)$. After TAVI procedure, 2 (2.2\%) patients needed permanent pacemaker implantation due to atrioventricular conduction block. Transfusion rates were higher in the AKIN group (13 vs. 22, $P=0.032$ ). Patients in AKIN and NRF groups did not show a significant difference in terms of diuretic, reninangiotensin-aldosterone blocker, and beta-blocker therapy (Table 1). The amount of CM was significantly higher in the AKIN group (148 vs. $138 \mathrm{ml}, P=0.028$ ). Eight patients died during the study period. Total mortality was higher in the AKIN group than in the NRF group (16.6\% vs. 2.9\%, $P=0.015$; Table 2 ).

\section{AKIN Predictors and Survival}

In univariate analysis, mPP, left ventricle ejection fraction, baseline creatinine, GFR, red blood cell transfusion, amount of $C M, S B P$, and DBP were found to be significantly associated with AKIN ( $P<0.01$ for all parameters). Thus, the multivariate regression analysis was performed with these variables; baseline creatinine, baseline GFR, amount of CM, and MPP were found to be significant predictors of AKIN (Table 3). The ROC analysis of the significant variables in multivariate regression analysis revealed that the cut-off value of mPP was $72 \mathrm{mmHg}$ to predict the development of AKIN (AUC, 0.813; 95\% Cl, 0.721-0.905; sensitivity, 72\%; specificity, 84\%; Figure 1). Mortality rates were significantly higher in AKIN patients. Kaplan-Meier survival curves for patients with and without AKIN (NRF group) showed a significantly lower survival rate up to 1 year in the overall AKIN group (16.6\% vs. $0.03 \%$ log-rank, $P=0.02$; Figure 2).

\section{DISCUSSION}

In our study, we found out that baseline creatinine, GFR, amount of CM, and lower MPP values were significantly associated with the development of AKIN in patients with TAVI.

Development of AKIN is strongly associated with increased major adverse cardiac events after TAVI procedure ${ }^{[9-11]}$. While $40 \%$ of the patients suffer from AKIN after SAVR, prevalence of AKIN ranges from $3.4 \%$ to $57 \%$ after TAVI procedure ${ }^{[10,12,13]}$. In accordance with previous studies, in our study 33 (21.2\%) patients developed AKIN after TAVI. Excessive CM usage, hypotension, rapid ventricular pacing, balloon aortoplasty, valve implantation, and embolisation of aortic plaque are considered intra-operative risk factors for AKIN after TAVI[12,14].

As it is well known, CM reduce oxygen availability to the renal medulla and cause renal ischemia ${ }^{[15]}$. Several studies 
Table 1. Clinical, laboratory, echocardiographic, and angiographic characteristics of the study population

\begin{tabular}{|c|c|c|c|}
\hline & HR-G $(n=52)$ & LR-G $(n=81)$ & $P$ value \\
\hline Age (years) & $78.8 \pm 6.9$ & $78.6 \pm 7.8$ & 0.369 \\
\hline Female gender, n (\%) & $29(55.8)$ & $43(53.1)$ & 0.451 \\
\hline STS score (\%) & $13.3 \pm 4.3$ & $14.6 \pm 6.7$ & 0.472 \\
\hline Logistic EuroSCORE (\%) & $29.4(15.9-38.2)$ & $24.7(14.8-35.3)$ & 0.093 \\
\hline AKIN, n (\%) & $22(42.3)$ & $8(9.9)$ & $<0.001$ \\
\hline Mortality, n (\%) & $5(9.6)$ & $3(3.7)$ & 0.153 \\
\hline Hemoglobin (g/dl) & $12.3 \pm 1.6$ & $12.4 \pm 1.8$ & 0.860 \\
\hline RBC transfusion, n (\%) & $15(28.8)$ & $20(24.7)$ & 0.785 \\
\hline Left ventricle ejection fraction (\%) & $41.9 \pm 10.4$ & $42.6 \pm 11.1$ & 0.726 \\
\hline NT-pro BNP (pg/ml) & $4188 \pm 1388$ & $3811 \pm 1258$ & 0.640 \\
\hline $\operatorname{AVA}\left(\mathrm{cm}^{2}\right)$ & $0.65 \pm 0.19$ & $0.64 \pm 0.21$ & 0.506 \\
\hline Mean gradient (mmHg) & $49.1 \pm 12.9$ & $50.2 \pm 10.6$ & 0.590 \\
\hline $\mathrm{SBP}(\mathrm{mmHg})$ & $120.1 \pm 9.8$ & $132.7 \pm 7.3$ & $<0.001$ \\
\hline $\mathrm{DBP}(\mathrm{mmHg})$ & $57.4 \pm 8.1$ & $69.6 \pm 9.4$ & $<0.001$ \\
\hline $\mathrm{mAP}(\mathrm{mmHg})$ & $78.1 \pm 9.7$ & $90.5 \pm 8.3$ & $<0.001$ \\
\hline CVP $(\mathrm{mmHg})$ & $13.2 \pm 2.9$ & $10.9 \pm 2.5$ & $<0.001$ \\
\hline $\mathrm{mPP}(\mathrm{mmHg})$ & $64.1 \pm 7.1$ & $79.7 \pm 5.3$ & $<0.001$ \\
\hline Creatinine (mg/dl) & $1.06 \pm 0.32$ & $1.01 \pm 0.29$ & 0.642 \\
\hline eGFR (ml/dk/1.73 m²) & $60.15 \pm 14.6$ & $62.69 \pm 16.7$ & 0.348 \\
\hline Diuretic, n (\%) & $10(19.2)$ & $13(16.0)$ & 0.443 \\
\hline RAAS blocker, n (\%) & $24(46.2)$ & $40(49.4)$ & 0.214 \\
\hline Beta-blocker, n (\%) & $29(55.7)$ & $50(61.7)$ & 0.494 \\
\hline Amount of contrast (ml) & $147(115-245)$ & $140.5(120-212)$ & 0.065 \\
\hline AR after TAVI ( $\geq$ grade II) & $6(11.5)$ & $10(12.3)$ & 0.646 \\
\hline Number of rapid pacing & $2.9 \pm 0.6$ & $2.7 \pm 0.4$ & 0.348 \\
\hline Rapid pacing duration (second) & $41(25-63)$ & $40(21-55)$ & 0.642 \\
\hline Previous CABG, n (\%) & $10(19.2)$ & $13(16.0)$ & 0.443 \\
\hline Previous PCl, n (\%) & $9(17.3)$ & $19(23.8)$ & 0.254 \\
\hline Diabetes mellitus, n (\%) & $19(36.5)$ & $27(33.3)$ & 0.422 \\
\hline Hypertension, n (\%) & $21(40.6)$ & $34(41.9)$ & 0.908 \\
\hline Hypercholesterolemia, n (\%) & $20(38.5)$ & $40(49.4)$ & 0.145 \\
\hline COPD, n (\%) & $20(38.5)$ & $26(32,1)$ & 0.285 \\
\hline CAD, n (\%) & $25(48.1)$ & $40(49.4)$ & 0.512 \\
\hline Intensive care unit (days) & $2(1.3-3.2)$ & $1.5(1.1-2.1)$ & 0.022 \\
\hline Hospital duration (days) & $5(3.5-6.2)$ & $4(3.3-5.8)$ & 0.027 \\
\hline
\end{tabular}

Values are number (\%), mean \pm standard deviation, or median $\left[25^{\text {th }}, 75^{\text {th }}\right.$ percentiles $]$.

$A K I N=$ acute kidney injury; $A R=$ aortic regurgitation; $A V A=$ aortic valve area; $B N P=b$-type natriuretic peptide; $C A B G=C o r o n a r y$ artery bypass graft; $C A D=$ coronary artery disease; $C O P D=$ chronic obstructive pulmonary disease; $C V P=$ central venous pressure; $\mathrm{DBP}=$ diastolic blood pressure; $\mathrm{eGFR}=$ estimated glomerular filtration rate; HR-G=High-risk group; LR-G=Low-risk group; $\mathrm{mAP}=$ mean arterial pressure; $\mathrm{mPP}=$ mean perfusion pressure; $\mathrm{NT}=\mathrm{N}$-terminal; $\mathrm{PCl}=$ percutaneous coronary intervention; RAAS=renin-angiotensin-aldosterone system; RBC=red blood cell; SBP=systolic blood pressure; STS=Society of Thoracic Surgeons; $\mathrm{TAVI}=$ transcatheter aortic valve implantation 
Table 2. Baseline characteristics in patients with or without AKIN (NRF group).

\begin{tabular}{|c|c|c|c|}
\hline & AKIN group $(n=30)$ & $\operatorname{NRF}(n=103)$ & $P$ value \\
\hline Age (years) & $78.2 \pm 7.3$ & $77.6 \pm 8.1$ & 0.699 \\
\hline Female gender, n (\%) & $14(46.7)$ & $58(56.3)$ & 0.234 \\
\hline STS score (\%) & $14.4 \pm 5.3$ & $13.2 \pm 5.7$ & 0.154 \\
\hline Logistic EuroSCORE (\%) & $27.5(14.7-36.1)$ & $26.5(15.0-37.1)$ & 0.742 \\
\hline Mortality, n (\%) & $5(16.6)$ & $3(2.9)$ & 0.015 \\
\hline Hemoglobin (g/dl) & $11.1 \pm 1.7$ & $11.3 \pm 1.8$ & 0.716 \\
\hline RBC transfusion, n (\%) & $13(43.3)$ & $22(21.4)$ & 0.032 \\
\hline Left ventricle ejection fraction, \% & $41.9 \pm 10.4$ & $42.6 \pm 11.1$ & 0.245 \\
\hline NT-pro BNP (pg/ml) & $4315 \pm 1492$ & $3656 \pm 1168$ & 0.524 \\
\hline $\operatorname{AVA}\left(\mathrm{cm}^{2}\right)$ & $0.61 \pm 0.22$ & $0.68 \pm 0.28$ & 0.605 \\
\hline Mean gradient $(\mathrm{mmHg})$ & $51.5 \pm 13.8$ & $49.2 \pm 10.8$ & 0.355 \\
\hline $\mathrm{SBP}(\mathrm{mmHg})$ & $121.9 \pm 10.6$ & $129.5 \pm 9.7$ & $<0.001$ \\
\hline $\mathrm{DBP}(\mathrm{mmHg})$ & $57.8 \pm 8.1$ & $66.9 \pm 7.7$ & $<0.001$ \\
\hline $\mathrm{mAP}(\mathrm{mmHg})$ & $79.5 \pm 7.8$ & $87.5 \pm 6.9$ & $<0.001$ \\
\hline CVP $(\mathrm{mmHg})$ & $13.6 \pm 3.2$ & $11.2 \pm 2.6$ & $<0.001$ \\
\hline $\mathrm{mPP}(\mathrm{mmHg})$ & $65.9 \pm 9.5$ & $76.3 \pm 7.4$ & $<0.001$ \\
\hline Creatinine (mg/dl) & $1.17 \pm 0.36$ & $0.99 \pm 0.26$ & 0.003 \\
\hline eGFR (ml/dk/1.73 m²) & $53.4 \pm 15.0$ & $64.1 \pm 15.4$ & 0.001 \\
\hline Diuretic, n (\%) & $8(26.7)$ & $15(14.6)$ & 0.548 \\
\hline RAAS blocker, n (\%) & $16(53.3)$ & $48(46.6)$ & 0.214 \\
\hline Beta-blocker, n (\%) & $18(60.0)$ & $51(49.5)$ & 0.406 \\
\hline Amount of contrast (ml) & $148(114-258)$ & $138(120-225)$ & 0.028 \\
\hline AR after TAVI ( $\geq$ grade II), n (\%) & $5(16.7)$ & $11(10.7)$ & 0.646 \\
\hline Number of rapid ventricular pacing, $n$ & $3 \pm 0.8$ & $2.7 \pm 0.4$ & 0.442 \\
\hline Rapid pacing duration (second) & $43(26-67)$ & $40.5(22-53)$ & 0.721 \\
\hline Previous CABG, n (\%) & $7(23.3)$ & $16(15.5)$ & 0.143 \\
\hline Previous $\mathrm{PCl}, \mathrm{n}(\%)$ & $8(26.7)$ & $20(19.4)$ & 0.254 \\
\hline Diabetes mellitus, n (\%) & $10(33.3)$ & $36(35.0)$ & 0.527 \\
\hline Hypertension, n (\%) & $11(36.7)$ & $44(42.7)$ & 0.174 \\
\hline Hypercholesterolemia, n (\%) & $11(36.7)$ & $49(47.6)$ & 0.199 \\
\hline COPD, n (\%) & $12(40.0)$ & $34(33.0)$ & 0.309 \\
\hline$C A D, n(\%)$ & $14(46.7)$ & $51(49.5)$ & 0.424 \\
\hline Intensive care unit (days) & $2(1.3-3.4)$ & $1.5(1.1-1.8)$ & 0.001 \\
\hline Hospital duration (days) & $5.5(3.4-6.8)$ & $4(3.1-5.2)$ & 0.014 \\
\hline
\end{tabular}

Values are number (\%), mean \pm standard deviation, or median $\left[25^{\text {th }}, 75^{\text {th }}\right.$ percentiles $]$.

$A K I N=$ acute kidney injury; $A R=$ aortic regurgitation; $A V A=$ aortic valve area; $B N P=b$-type natriuretic peptide; $C A B G=c o r o n a r y$ artery bypass graft; $C A D=$ coronary artery disease; $C O P D=$ chronic obstructive pulmonary disease; $C V P=$ central venous pressure; $\mathrm{DBP}=$ diastolic blood pressure; $\mathrm{eGFR=estimated} \mathrm{glomerular} \mathrm{filtration} \mathrm{rate;} H R-G=H i g h-$ risk group; $L R-G=L o w-r i s k$ group; $\mathrm{mAP}=$ mean arterial pressure; $\mathrm{mPP}=$ mean perfusion pressure; $\mathrm{NT}=\mathrm{N}$-terminal; $\mathrm{PCl}=$ percutaneous coronary intervention; RAAS=renin-angiotensin-aldosterone system; RBC=red blood cell; SBP=systolic blood pressure; STS=Society of Thoracic Surgeons; $\mathrm{TAV}=$ transcatheter aortic valve implantation 
Table 3. Results of multivariate regression analysis for predictors of post-TAVI AKIN.

\begin{tabular}{l|c|c|c}
\hline & Odds ratio & $\mathbf{9 5 \%} \mathbf{C l}$ & $\boldsymbol{P}$ value \\
\hline $\mathrm{mPP}(\mathrm{mmHg})$ & 5.1 & $2.7-8.5$ & 0.013 \\
\hline Amount of contrast $(\mathrm{ml})$ & 7.0 & $3.2-11.1$ & 0.008 \\
\hline RBC transfusion, $\mathrm{n}$ & 0.7 & $0.3-1.4$ & 0.385 \\
\hline Baseline creatinine $(\mathrm{mg} / \mathrm{dl})$ & 2.1 & $1.1-3.3$ & 0.044 \\
\hline Baseline GFR $\left(\mathrm{ml} / \mathrm{min} / 1.73 \mathrm{~m}^{2}\right)$ & 2.6 & $0.4-4.1$ & 0.032 \\
\hline SBP $(\mathrm{mmHg})$ & 0.5 & $0.4-1.1$ & 0.782 \\
\hline DBP $(\mathrm{mmHg})$ & 0.6 & $0.7-2.0$ & 0.582 \\
\hline Left ventricle ejection fraction (\%) & 1.3 & 0.248 \\
\hline
\end{tabular}

$\mathrm{AKIN}=$ acute kidney injury; $\mathrm{Cl}=$ confidence interval; $\mathrm{DBP}=$ diastolic blood pressure; $\mathrm{GFR}=$ glomerular filtration rate; $\mathrm{mPP}=\mathrm{mean}$ perfusion pressure; $\mathrm{RBC}=$ red blood cell; $\mathrm{SBP}=$ systolic blood pressure; $\mathrm{TAVI}=$ transcatheter aortic valve implantation

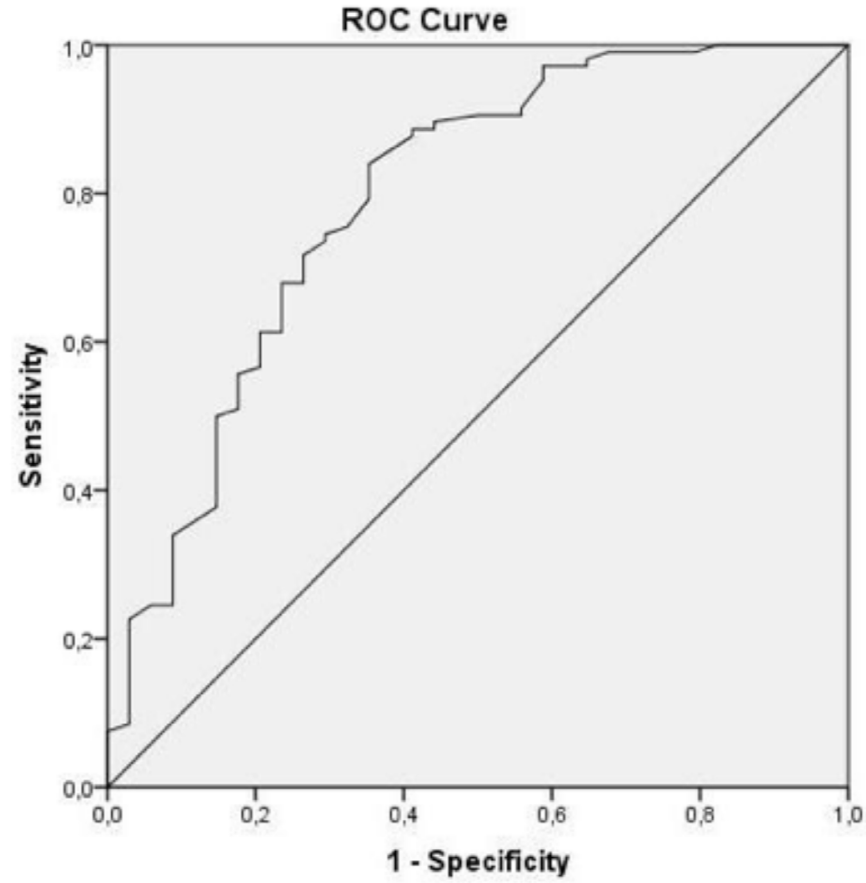

Fig. 1 - ROC curve of mean perfusion pressure. The mean perfusion pressure value which can predict the acute kidney injury development was determined as $72 \mathrm{mmHg}$ in ROC analysis [AUC: 0.813 (95\% Cl; 0.721-0.905); sensitivity, 72\%; specificity, 84\%]. AUC = area under the curve; $\mathrm{Cl}=$ confidence interval; $\mathrm{ROC}=$ receiver operating characteristics.

demonstrated that CM/GFR and CM/creatinine clearance $(\mathrm{CrCl})$ rates in invasive procedures are predictors of renal failure ${ }^{[16-18]}$. It can be useful to calculate basal GFR and $\mathrm{CrCl}$ before TAVI, to be used to calculate upper limits for CM. The mAP might be decreased below $50 \mathrm{mmHg}$ during rapid ventricular pacing. These hypotensive stages can contribute to the development of AKIN. Therefore, number and duration of rapid ventricular

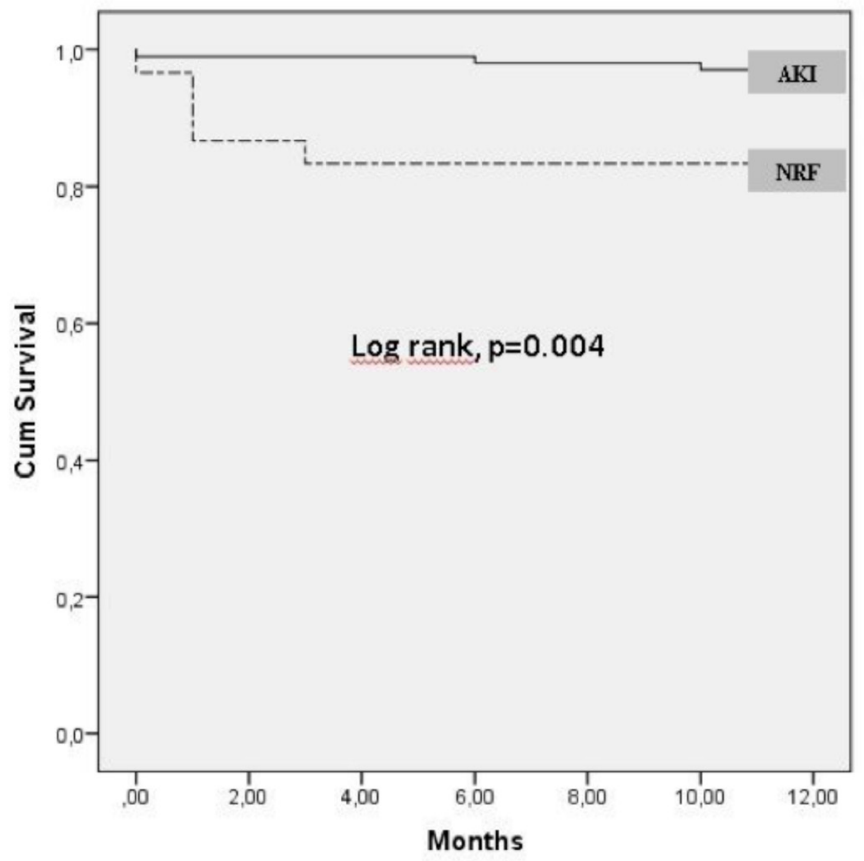

Fig. 2 - Kaplan-Meier curves for overall survival in AKIN and nonAKIN (NRF) groups. AKIN = acute kidney injury; NRF = normal renal functions.

pacing used for our patients during TAVI were recorded in our study. Although basal kidney function tests are important for impairment of renal function, other factors, such as mPP, amount of $\mathrm{CM}$, and rapid ventricular pacing, should be kept in mind to predict renal impairment.

In addition to many factors affecting the development of AKIN, hemodynamic parameters of patients before an invasive procedure are also important indicators of potential renal complications. Renal hypoperfusion is the most important cause of AKIN after SAVR and TAVI ${ }^{[11,19]}$. Renal perfusion pressure is the 
most important predictor of renal blood flow. A normal renal perfusion pressure should be between 60 and $100 \mathrm{mmHg}^{[20]}$. However, there isn't any non-invasive method that can directly measure it. Renal perfusion pressure can be estimated using mPP, mAP, and CVP levels. Especially, mPP calculated with mAP and CBP is shown to be an important indicator for the continuation of $\mathrm{NRF}^{[21]}$. A strong association has been demonstrated between mPP levels and GFR in various diseases ${ }^{[22]}$. Based on the study results, mPP values obtained with invasive monitorization in advanced AS patients were found to be a significant factor in predicting the development of AKIN. The predictive value of AKIN development was calculated as $72 \mathrm{mmHg}$ using ROC analysis (Figure 1). The percentage of AKIN was much higher in the HR-G group ( $42.3 \%$ vs. $9.9 \%, P<0.001)$. The calculation of $\mathrm{mPP}$ is based on the difference between $m A P$ and $C V P$. Since $M A P$ values of the HR-G group were lower and CVP values were higher, $\mathrm{mPP}$ values in this group were low (Table 1). The value of mPP is more closely associated with renal perfusion pressure, compared to mAP and CVP ${ }^{[21,22]}$.

\section{Limitations of the Study}

The main limitation of this study is the small number of patients included. Additional information can be obtained in longer follow-up periods. In our study, TAVI using balloon expandable prosthesis was performed, and it would be useful to conduct similar studies with a self-expandable prosthesis.

\section{CONCLUSION}

These findings led to the conclusion that among the patients with similar renal functions, who received a similar amount of CM, those with lower mPP are at higher risk for AKIN development. A model was created with regression analysis to identify the factors affecting the development of AKIN in our study.

The mortality rate in patients who developed AKIN after TAVI ranges from $7.8 \%$ to $29 \%{ }^{[6,23]}$. In our study, the one-year mortality rate was $16.7 \%$ in patients who developed AKIN and $2.9 \%$ in patients who did not. The presence of AKIN increased the mortality in a one-year period approximately by 5.5 times. Therefore, preventing the development of AKIN should be an important goal to minimise TAVI complications.

In our study, the amount of $\mathrm{CM}$, basal kidney function tests, and lower mPP levels ( $\mathrm{mPP}<72 \mathrm{mmHg}$ ) were strongly associated with the development of AKIN after TAVI. Further studies are needed to evaluate the association between MPP and AKIN in patients treated with TAVI.

\section{Authors' roles \& responsibilities}

IG Analysis and interpretation of data; drafting the paper; revising the work; approval of the final version

LC Analysis and interpretation of data; drafting the paper; revising the work; approval of the final version

BS Conception and design of the work; acquisition of data; analysis and interpretation of data; drafting the paper; revising the work; approval of the final version

MZ Conception and design of the work; acquisition of data; analysis and interpretation of data; drafting the paper; revising the work; approval of the final version

MBA Conception and design of the work; acquisition of data; analysis and interpretation of data; drafting the paper; revising the work; approval of the final version

HK Conception and design of the work; acquisition of data; analysis and interpretation of data; drafting the paper; revising the work; approval of the final version

ZC Conception and design of the work; acquisition of data; analysis and interpretation of data; drafting the paper; revising the work; approval of the final version

BY Conception and design of the work; acquisition of data; analysis and interpretation of data; drafting the paper; revising the work; approval of the final version

SU Conception and design of the work; acquisition of data; analysis and interpretation of data; drafting the paper; revising the work; approval of the final version

HD Conception and design of the work; acquisition of data; analysis and interpretation of data; drafting the paper; revising the work; approval of the final version

\section{REFERENCES}

1. Eveborn GW, Schirmer H, Heggelund G, Lunde P, Rasmussen K. The evolving epidemiology of valvular aortic stenosis. The Tromso study. Heart. 2013;99(6):396-400.

2. Adams DH, Popma JJ, Reardon MJ, Yakubov SJ, Coselli JS, Deeb GM, et al. Transcatheter aortic-valve replacement with a self-expanding prosthesis. N Engl J Med. 2014;370(19):1790-8.

3. Turina J, Hess O, Sepulcri F, Krayenbuehl HP. Spontaneous course of aortic valve disease. Eur Heart J. 1987;8(5):471-83.

4. Cribier A. Development of transcatheter aortic valve implantation (TAVI): a 20-year odyssey. Arch Cardiovasc Dis. 2012;105(3):146-52.

5. Dangas G, lakovou I, Nikolsky E, Aymong ED, Mintz GS, Kipshidze NN, et al. Contrast-induced nephropathy after percutaneous coronary interventions in relation to chronic kidney disease and hemodynamic variables. Am J Cardiol. 2005;95(1):13-9.

6. Bagur R, Webb JG, Nietlispach F, Dumont E, De Larochellière R, Doyle D, et al. Acute kidney injury following transcatheter aortic valve implantation: predictive factors, prognostic value, and comparison with surgical aortic valve replacement. Eur Heart J. 2010;31(7):865-74.

7. Kappetein AP, Head SJ, Genereux P, Piazza N, van Mieghem NM, Blackstone $\mathrm{EH}$, et al. Updated standardized endpoint definitions for transcatheter aortic valve implantation: the Valve Academic Research Consortium-2 consensus document. Eur Heart J. 2012;33(19):2403-18.

8. Vahanian A, Alfieri O, Andreotti F, Antunes MJ, Barón-Esquivias G, Baumgartner $\mathrm{H}$, et al. ESC Committee for Practice Guidelines (CPG); Joint Task Force on the Management of Valvular Heart Disease of the European Society of Cardiology (ESC); European Association for CardioThoracic Surgery (EACTS): Guidelines on the management of valvular heart disease (version 2012): the Joint Task Force on the Management of valvular heart disease of the European Society of Cardiology (ESC) and the European Association for Cardio-Thoracic Surgery (EACTS). Eur J Cardiothorac Surg. 2012;42(4):S1-44. 
9. Elhmidi Y, Bleiziffer S, Deutsch MA, Krane M, Mazzitelli D, Lange R, et al. Acute kidney injury after transcatheter aortic valve implantation: incidence, predictors and impact on mortality. Arch Cardiovasc Dis. 2014;107(2):133-9.

10. Najjar M, Salna M, George I. Acute kidney injury after aortic valve replacement: incidence, risk factors and outcomes. Expert Rev Cardiovasc Ther. 2015;13(3):301-16.

11. Genereux P, Kodali SK, Green P, Paradis JM, Daneault B, Rene G, et al. Incidence and effect of acute kidney injury after transcatheter aortic valve replacement using the new valve academic research consortium criteria. Am J Cardiol. 2013;111(1):100-5.

12. Thongprayoon C, Cheungpasitporn W, Srivali N, Ungprasert $P$, Kittanamongkolchai W, Greason KL, et al. Acute kidney injury after transcatheter aortic valve replacement: a systematic review and metaanalysis. Am J Nephrol. 2015;41(4-5):372-82.

13. Mack MJ, Leon MB, Smith CR, Miller DC, Moses JW, Tuzcu EM, et al. 5-year outcomes of transcatheter aortic valve replacement or surgical aortic valve replacement for high surgical risk patients with aortic stenosis (PARTNER 1): a randomised controlled trial. Lancet. 2015;385(9986):2477-84.

14. Scherner M, Wahlers T. Acute kidney injury after transcatheter aortic valve implantation. J Thorac Dis. 2015;7(9):1527-35.

15. Rudnick MR, Kesselheim A, Goldfarb S. Contrast-induced nephropathy: how it develops, how to prevent it. Cleve Clin J Med. 2006;73(1):7580, 83-7.

16. Wang XC, Fu XH, Wang YB, Jia XW, Wu WL, Gu XS, et al. Prediction of contrast-induced nephropathy in diabetics undergoing elective percutaneous coronary intervention: role of the ratio of contrast medium volume to estimated glomerular filtration rate. Chin Med J. 2011;124(6):892-6.

17. Gul I, Zungur M, Tastan A, Okur FF, Damar E, Uyar S, et al. The importance of contrast volume/glomerular filtration rate ratio in contrast-induced nephropathy patients after transcatheter aortic valve implantation. Cardiorenal Med. 2015;5(1):31-9.

18. Barbieri L, Verdoia M, Marino P, Suryapranata H, De Luca G. Novara Atherosclerosis Study Group. Contrast volume to creatinine clearance ratio for the prediction of contrast-induced nephropathy in patients undergoing coronary angiography or percutaneous intervention. Eur J Prev Cardiol. 2016;23(9):931-7.

19. Hobson CE, Yavas S, Segal MS, Schold JD, Tribble CG, Layon AJ, et al. Acute kidney injury is associated with increased long-term mortality after cardiothoracic surgery. Circulation. 2009;119(18):2444-53.

20. Loutzenhiser R, Griffin K, Williamson G, Bidani A. Renal autoregulation: new perspectives regarding the protective and regulatory roles of the underlying mechanisms. Am J Physiol Regul Integr Comp Physiol. 2006;290(5):R1153-67.

21. Panwar R, Lanyon N, Davies AR, Bailey M, Pilcher D, Bellomo R. Mean perfusion pressure deficit during the initial management of shock: an observational cohort study. J Crit Care. 2013;28(5):816-24.

22. Ostermann M, Hall A, Crichton S. Low mean perfusion pressure is a risk factor for progression of acute kidney injury in critically ill patients: a retrospective analysis. BMC Nephrol. 2017;18(1):151.

23. Nuis RJ, Rodés-Cabau J, Sinning JM, van Garsse L, Kefer J, Bosmans J, et al. Blood transfusion and the risk of acute kidney injury after transcatheter aortic valve implantation. Circ Cardiovasc Interv. 2012;5(5):680-8. 